\title{
SOLAR POWER INSTALLATION FOR THE TERRITORY OF SIBERIA
}

\author{
Arman Boyakhchyan ${ }^{* 1}$, Alyona Okhorzina ${ }^{1}$, Aygul Kshalova ${ }^{2}$ \\ ${ }^{1}$ Tomsk Polytechnic University, 634050, Tomsk, Russia \\ ${ }^{2}$ Karaganda State Technical University, 100027, Karaganda
}

\begin{abstract}
This article describes combined solar systems with liquid cooling are considered in this article. Solar power systems have long been popular in Europe, but in the Siberian climate these systems were considered to be inappropriate. The paper argues that such installations may be used even in Siberia, and in some regions it will be economically profitable. In this article describe an installation that was assembled to carry out field experiments.
\end{abstract}

\section{Introduction}

The territory of Siberia occupies $70 \%$ of the territory of Russia, which is home to 25 million people. The most of the population lives in remote rural areas, where there is no centralized power supply. Because In the agriculture of Siberia, large-scale work on livestock farming is carried out, this requires fuel and energy costs. The solution of the problem of ensuring the energy needs of the population, agriculture and small industry in regions remote from centralized energy networks, provided they are environmentally friendly, can be solved by introducing autonomous alternative energy systems [1].

Solar panels use sunlight, not heat and not even sunlight. Therefore, in the winter they will work quite well, provided that the owner removes snow from them, although they will also work under snow. And sometimes, the snow thaws from the work of photocells.

In cloudy weather, the panels will produce less light than usual, but in general, there are rarely cases when the battery does not have enough time to charge during the day. But in a sunny, frosty weather, the batteries will be very effective $[2,3]$.

In winter, the tilt angle (Figure 1) of solar panels is very important, as the sun goes lower and this also affects their productivity. The vertical position also helps the batteries not to be covered with snow.

\footnotetext{
* Corresponding author: bojahchyan@yandex.ru
} 


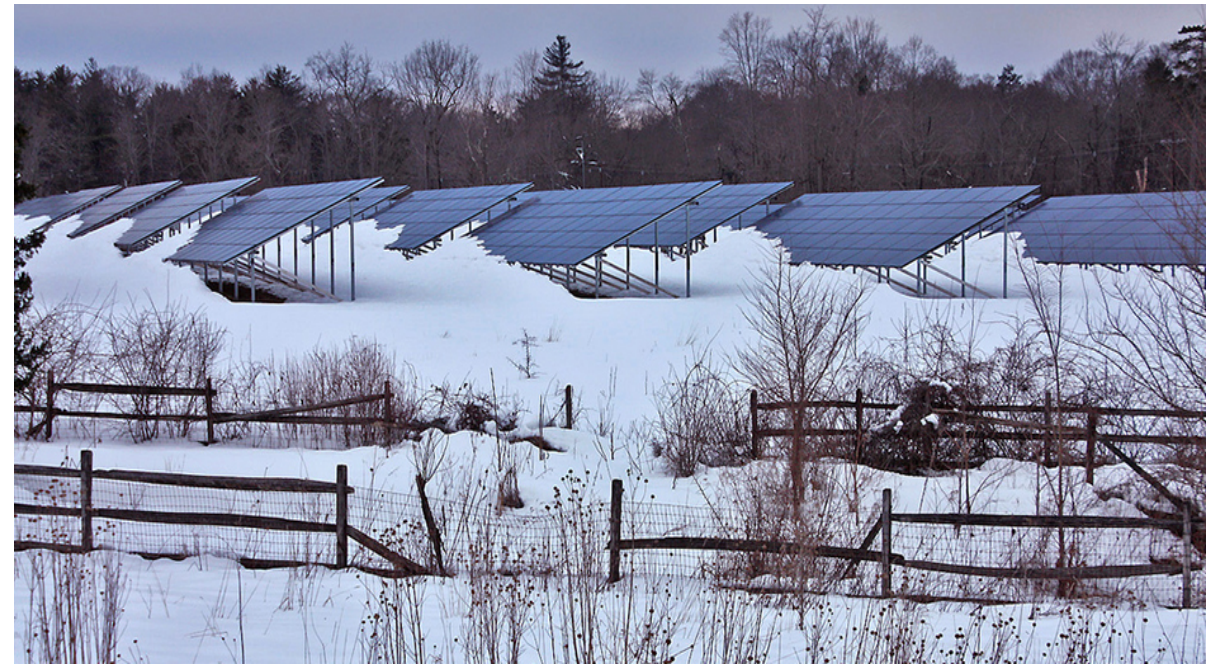

Fig.1. Solar panels in Siberia.

The creation of an economical power plant that converts solar energy into useful (thermal and electrical) energy will solve the problems of energy supply in the vast territory of Siberia, and will reduce losses in agriculture [4].

To increase efficiency and economy, including the advisability of using solar power plants on the territory of Siberia, it is necessary to use concentrators, cooling systems and orientation in the sun [5].

\section{Experimental verification}

For research, an installation was assembled, which is a hybrid system that converts solar energy into electrical and thermal energy. Sunlight, incident on the photoelectric module, is converted into electrical energy. The production of heat is due to the cooling of photovoltaic modules. Increase in energy production is achieved by introducing a low concentrating concentrator. The concentrator is a reflecting surface consisting of several segments, by means of which the concentration of solar radiation rises 2-3 times.

The incoming radiation flux falls on the concentrator and is reflected in the FM. The plane of the solar module is located perpendicular to the flux of reflected radiation. For work in the cold season, you can use an additional cover, which will also protect the concentrator and photovoltaic modules from atmospheric precipitation and reduce the outflow of heat to the environment.

To increase the power of the system used to track the sun.

To increase energy production without losses, it is necessary to introduce a cooling system that maintains the panel temperature below $40^{\circ} \mathrm{C}$. At the same time, if possible, the system will circulate water in the system to ensure its heating.A laboratory experiment using a point heating source to test how the surface of the solar panel heats up and how heat dissipates from it.

The halogen spotlight NFL-FH1-150 W was used as a source of light and heat. During the heating process, the thermograms were recorded using the Testo 876 thermal imager. The experiment was carried out until the maximum heating of the solar panel surface was obtained (Figure 2). 

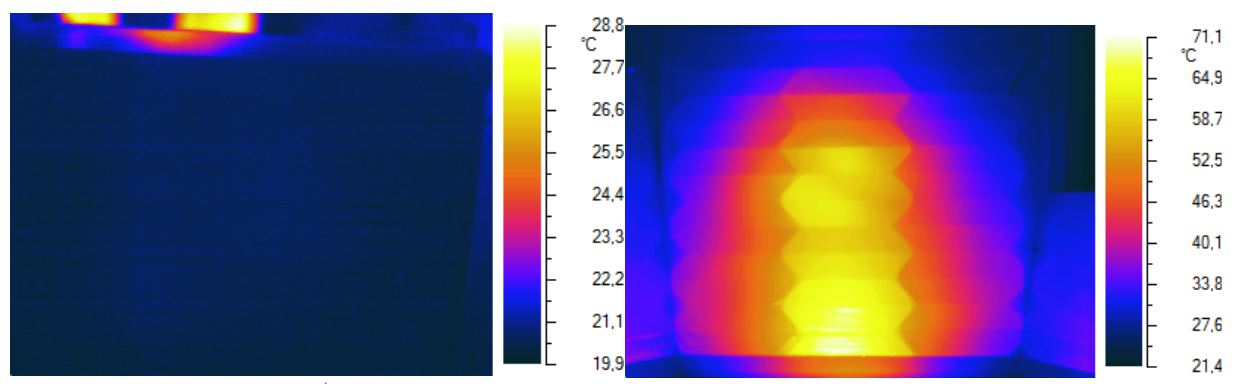

a)

Fig.2. Thermograms: a) before heating; b) after the heating is turned on.

The real experiment was conducted in Tomsk. In the process of heat dissipation, tap water with a temperature of $150^{\circ} \mathrm{C}$ was applied to the heat exchange system. The system took about 20 minutes, so that the temperature at the maximum heating point decreased by 40 degrees.

A plant was assembled using a concentrating system. At the first stage, the heating time of the entire system was monitored on a sunny, clear day. At the second stage, the cooling system was connected, and observations were made for the cooling quality of the system Figure 3,4.
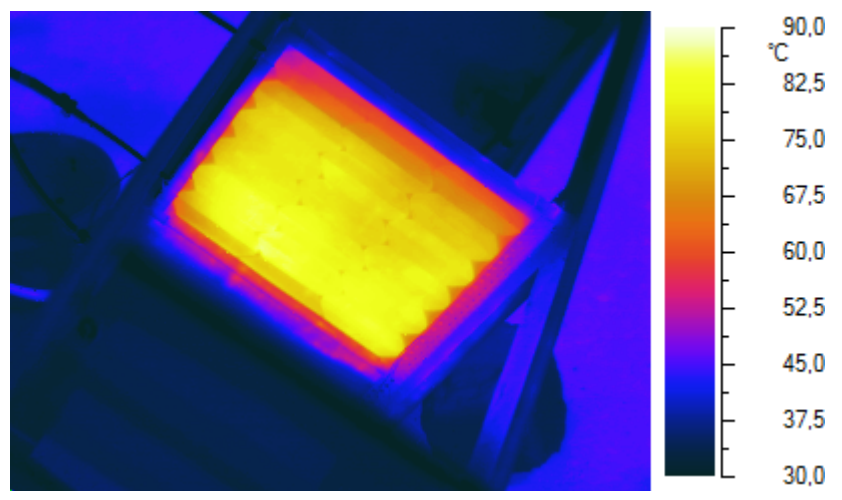

Fig.3. Thermogram during heating.

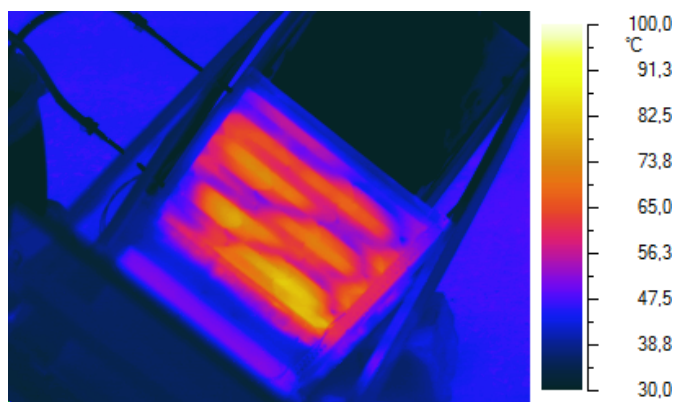

Fig.4. Thermogram with cooling.

\section{Results of research}


As a result of the full-scale experiment, it was revealed that this system works. Heating of the solar panel surface with concentrating panels occurs quickly. Reaching a dangerous temperature for solar panel at $90^{\circ} \mathrm{C}$ occurs within 10 minutes. The cooling system copes with its task.

\begin{tabular}{|c|c|c|c|c|}
\hline \multicolumn{5}{|c|}{ Table 1. Experimental data } \\
\hline $\begin{array}{l}\text { 12-th of } \\
\text { Sentember }\end{array}$ & \multicolumn{2}{|c|}{$V=3.5$ liters } & \multirow{2}{*}{$\begin{array}{l}S r=560 \\
t p v,{ }^{0} \mathrm{C}\end{array}$} & \multirow{2}{*}{$\begin{array}{c}t a m b=26.5 \\
t b,{ }^{0} \mathrm{C}\end{array}$} \\
\hline time & $U, \mathrm{~B}$ & $I, \mathrm{~A}$ & & \\
\hline $14: 15$ & 19.14 & 0.67 & 48 & \\
\hline $14: 21$ & 18.15 & 1.23 & 44.9 & \\
\hline $14: 29$ & & & 47 & 13 \\
\hline $14: 30$ & & & 48.3 & \\
\hline $14: 48$ & 17.97 & 1.87 & 45 & 40 \\
\hline $14: 55$ & & & 48 & 15 \\
\hline 15:01 & 18.17 & 0.52 & 43.3 & \\
\hline $15: 15$ & 17.98 & 0.23 & 41.2 & 34 \\
\hline $\begin{array}{c}\text { 15-th of } \\
\text { September }\end{array}$ & \multicolumn{2}{|c|}{$V=10$ liters } & $S r=550$ & $\operatorname{tamb}=17.5$ \\
\hline time & $U, \mathrm{~B}$ & $I, \mathrm{~A}$ & $t p v,{ }^{0} \mathrm{C}$ & $t b,{ }^{0} \mathrm{C}$ \\
\hline $13: 48$ & 16.76 & 0.05 & 28.1 & 16 \\
\hline 13:56 & 20 & 1.18 & 48.5 & 16 \\
\hline $14: 15$ & 17.6 & 0.97 & 56.4 & 16 \\
\hline $14: 29$ & 18.9 & 0.53 & 44.2 & 22 \\
\hline $14: 40$ & 19.1 & 0.46 & 38.4 & 25.5 \\
\hline $14: 55$ & 19.1 & 0.65 & 41.8 & 28 \\
\hline 15:06 & 18.97 & 0.48 & 41.6 & 29 \\
\hline $15: 17$ & 19 & 0.61 & 42.7 & 31 \\
\hline $15: 25$ & 18.81 & 0.4 & 44 & 31 \\
\hline
\end{tabular}

\section{Conclusion}


Experiments have shown that a combined solar installation allows the conversion of solar energy not only into electrical energy, but also to extract the useful thermal energy that is used to heat water. This installation should be used to increase the efficiency and profitability of using solar energy to generate useful energy.

\section{References}

[1] A.V. Yurchenko, F.V. Savrasov, V.I. Yurchenko, Izvestiya Tomsk Polytechnic University 314, 43 (2009)

[2] N.N. Bakin, V.K. Kovalevsky, A.P. Plotnikov, A.V. Yurchenko, Optics of the atmosphere and ocean 11,1337 (1998)

[3] A. Yurchenko, V. Syriamkin, A. Okhorzina, N. Kurkan, IOP Conf. Ser.: Mater. Sci. Eng. 81, 012097 (2015)

[4] A. Yurchenko, M. Kitaeva, A. Okhorzina, Proceedings of 7th International Forum on strategic Technology, IFOST 2015, (2018)

[5] A.V. Yurchenko, M.V. Kitaeva, A.V. Skorokhodov, A.V. Okhorzina, Polzunovskii vestnik, 213 (2012) 